\title{
PROMOTING SCHOOL-CENTERED PROFESSIONAL DEVELOPMENT THROUGH TEACHING PORTFOLIOS
}

\section{A Case Study}

\author{
Jianzhong Xu \\ Mississippi State University
}

\begin{abstract}
This article presents a case study in which teaching portfolios evolved as a mechanism to promote school-centered professional development in an urban elementary school. Data were primarily derived from open-ended interviews with the principal, staff developer, and teachers, complemented by other relevant documentation. This study examines the impact of the portfolio project on professional learning and professional collaboration. The data reveal that a wide range of conditions contributed to professional learning and collaboration through teaching portfolios. These conditions can be categorized into three groups: (a) conditions supporting both professional learning and professional collaboration in general, (b) conditions more specifically supporting professional learning, and (c) conditions more specifically supporting professional collaboration. The article discusses both methodology and results in the context of recent theoretical frameworks. In addition, it suggests directions for future research, theory, and practice related to school-centered professional development for teachers.
\end{abstract}

Keywords: professional development; teaching portfolio; case study; elementary school

\begin{abstract}
On June 12,1995, almost all of the teachers at Avery ${ }^{1}$ came to the school library during their respective lunch periods. Along with the principal, Ms. Fry, and the staff developer, Ms. Kirk, they gathered to congratulate five teachers who had just completed their teaching portfolios.

During the celebration, one teacher explained the purpose of her portfolio. Facing frustration at the beginning of the year, she wanted to figure out how to better meet the needs of her students in reading. To do so, she chose three students, one each from the top, middle, and bottom reading levels of her firstgrade class. With the aid of running records, she tried to address their needs so they could advance to the next level. Her portfolio documented the journey
\end{abstract}

she had traveled since the beginning of the school year.

As each of the five teachers explained their portfolios, other teachers attentively listened and became excited while enjoying the lunch provided by Ms. Fry. The celebration climaxed when Ms. Kirk proposed a toast and all of the staff members in the room stood up, cheering the teachers for their accomplishments and welcoming them as the newest members of "the portfolio community." When people left, most of them took copies of several newly completed portfolios to read carefully later.

Avery was an urban elementary school that used teaching portfolios as a means to promote

\section{ACKNOWLEDGMENTS}

The author thanks Ann Lieberman, Mary Anne Raywid, and Jacqueline Access for their valuable comments on an earlier draft. The author would also like to thank Linda Darling-Hammond for her support in conducting this study as well as the principal and staff members at the school for their cooperation. Finally, the author thanks Editor Marilyn Cochran-Smith and two anonymous reviewers for their provocative comments and insightful suggestions.

Journal of Teacher Education, Vol. 54, No. 4, September/October 2003 347-361

DOI: $10.1177 / 0022487103255015$

(C) 2003 by the American Association of Colleges for Teacher Education 
teachers' professional development. Creating a teaching portfolio, which requires teachers to focus in-depth in one specialized area of interest, gained a surprising momentum in the school. Starting with a handful of teachers who volunteered, the portfolio project snowballed in 2 years to engage almost all of the teachers in the school. It emboldened them to become more reflective of their teaching and provided opportunities for them to engage in constructive conversation about their work with their colleagues in the school community.

A growing literature articulates the need to address the fundamental mismatch between new demands on teachers and existing opportunities for their professional growth (DarlingHammond \& McLaughlin, 1995; Lieberman, 1995; Little, 1993; Wilson \& Berne, 1999). A few new models for effective professional development have emerged in recent years (Miller, 1998; Wilson \& Berne, 1999). These models share some common characteristics and can be categorized as school-centered professional development. This new approach to professional development encourages teachers to learn with and from colleagues in their school communities, to reflect critically on their daily practices, and to enhance their capacity to understand complex subject matters from the perspectives of diverse learners. Yet, scant research exists to understand the nature of school-centered professional development (Loucks-Horsley, 1995; Wilson \& Berne, 1999). Little is known about mechanisms (Daniel \& Stallion, 1996; Wilson \& Berne, 1999) and supporting conditions (Dilworth \& Imig, 1995; Little, 1993; McDiarmid, 1994; Teitel, Ricci, \& Coogan, 1998) for promoting school-centered professional development, let alone about the role of teaching portfolios in this process.

This article presents a case study in which the teaching portfolios evolved as a mechanism to promote school-centered professional development in an elementary school. Specifically, it focuses on two research questions: What was the impact of the teaching portfolios on professional learning and collaboration? What were the enabling conditions that helped foster school-centered professional development through this portfolio project?

\section{RELATED LITERATURE}

School-centered professional development is increasingly viewed as central to advancing the present reform agenda (Darling-Hammond \& McLaughlin, 1995; Fullan, 1995b; Lieberman, 1995; Little, 1993; Sparks, 1995; Wilson \& Berne, 1999). Little (1993) outlined the following five streams of educational reform: in subject matter teaching; on problems of equity in diverse student populations; in the nature, extent, and use of student assessment; in the social organization of schooling; and in the professionalization of teaching. She argued that the traditional training-and-coaching model is no longer adequate for the demands of these reforms because many of these demands require teachers to grapple with what broad principles look like in daily practice rather than to simply adopt practices thought to be universally effective. Thus, "the school workplace is both the most crucial and the most complex of domains in which we play out the possibilities for teachers' professional development" (Little, 1993, p. 21).

Similarly, Sparks (1995) argued that constructivist teaching is best learned through a new model of professional development in which teachers collaborate with peers "to make sense of the teaching/learning process in their own contexts" (p. 3). Darling-Hammond and McLaughlin (1995) stated that "teaching for understanding relies on teachers' abilities to see complex subject matter from the perspectives of diverse students" (p. 597). Therefore, the focus of professional development needs to shift from supporting "teachers' acquisition of new skills or knowledge" to providing occasions for them "to reflect critically on their practice and to fashion new knowledge and beliefs about content, pedagogy, and learners" (Darling-Hammond \& McLaughlin, 1995, p. 597).

Others argue from the perspective of how to support teacher development. Situated cognition theory posits that knowledge and skills are better learned in contexts that reflect how knowledge is obtained and applied in every- 
day situations (Kirshner \& Whitson, 1997). Lieberman (1995) held that "the best way for teachers to learn" is through "their own involvement in defining and shaping the problems of practice" (p. 592) in the school context and with the support of their colleagues. Loughran's (1994) work lends further empirical support to this view of teacher development. Based on interviews with 75 science teachers across Australia, he found that these teachers attached more importance to learning informally with colleagues in their own schools than learning in externally organized professional development activities.

Although traditional forms of professional development have been criticized for being decontextualized, other opportunities for teacher learning and collaboration are still rare and sporadic at best (Lord, 1994). Although educators have become increasingly sophisticated about the process of conceptualizing changes, there are still few opportunities and little support for teachers to learn from and with colleagues in their daily environment (Daniel \& Stallion, 1996; Darling-Hammond \& McLaughlin, 1995; Fullan, 1995a). Furthermore, very little research has been conducted to understand the nature of new models of professional development (Wilson \& Berne, 1999). The work is so rare that Loucks-Horsley (1995) observed that these models are currently more theoretical than real. More recently, Wilson and Berne's (1999) review of research on professional development drew a similar conclusion that "we know as little about what teachers learn in these kinds of forums as we do about what teachers learn in traditional staff development and in-service" (p. 176). Thus, "our readiness to embrace these new principles may, in fact, be rooted in a desire to escape collective bad memories of drab professional development workshops rather than in sound empirical work" (Wilson \& Berne, p. 176).

Particularly, there is little empirical research that examines just what mechanisms and supporting conditions are needed to promote school-centered professional development. School-centered professional development requires more than downloading resources and activities to a school site (Little, 1993); it also calls for a set of supporting conditions (McDiarmid, 1994; Teitel et al., 1998) and adequate opportunities to learn within the teachers' day-to-day work (Dilworth \& Imig, 1995). Daniel and Stallion (1996) studied professional development activities in Kentucky since 1990 based on data collected from principals and teachers in 44 schools across the state. Their study found that the professional development options available in most schools were still the traditional forms of seminars, workshops, and formal higher education courses, whereas only a very few schools had begun exploring and providing other opportunities such as mentoring and encouraging teachers to be researchers. Thus, the authors called for "a method for providing follow-up or ongoing experiences so practitioners can become experts" (Daniel \& Stallion, 1996, p. 32). Wilson and Berne (1999) go beyond this and propose that "all research on teacher learning and the acquisition of professional knowledge would benefit from more systematic theorizing about the mechanisms by which teachers learn" (p. 204).

Teaching portfolios are perceived as a good fit with the new models of professional development (Lyons, 1998b; Stone, 1998; Wolf \& Dietz, 1998). A teaching portfolio is defined as a structured collection of evidence of a teacher's work across diverse contexts and over time and framed by deliberation and reflective writing (Shulman, 1998; Wolf \& Dietz, 1998). Wolf and Dietz (1998) have identified the following three portfolio models that have emerged in practice: the learning portfolio, the assessment portfolio, and the employment portfolio. Learning portfolios are personalized collections of teacher work to promote reflection and ownership over the learning process. Assessment portfolios are selective collections of teacher work gathered according to structured guidelines set by an educational organization to provide information about a teacher's effectiveness. Employment portfolios are customized collections of information presented to prospective employers to help them evaluate a teacher's suitability for a professional position. 
Recently, teaching portfolios have seized educators' imagination for their power to capture the complexities of teaching and learning as they develop over time in authentic settings (Grant \& Huebner, 1998). Increasingly, they have become a regular feature in many educational programs at the national, state, district, school, and university levels (Wolf, 1996). Teaching portfolios, used as learning portfolios (Wolf \& Dietz, 1998), are perceived to be congruent with the new models of professional development for in-service teachers. However, most of the professional literature has focused on their use with preservice teachers (Lyons, 1998b; Wolf \& Dietz, 1998). On a few occasions when efforts were made to move the use of teaching portfolios beyond preservice years, the studies were limited to either a group of new teachers (Bartell, Kaye, \& Morin, 1998; Lyons, 1998a; Perez, Swain, \& Hartsough, 1997) or a few volunteering experienced teachers (Teitel et al., 1998; Wagenen \& Hibbard, 1998). Few if any attempts have been made to examine the impact of teaching portfolios on teachers at different developmental stages-learning from and with their more or less experienced colleagues in the context of their schoolwide communities.

Thus, this study may be viewed as bridging a gap in professional development research. It seeks to better understand how one school used the teaching portfolios as a primary mechanism supported by a set of conditions to promote professional learning and collaboration among teachers at different developmental stages. By examining how this school fostered professional development opportunities in the day-today life of teachers, educators can better understand what school-centered professional development entails in real settings through teaching portfolios, how it affects those who are expected to learn from it, and how such a change might be nurtured in other school communities.

\section{RESEARCH DESIGN}

Avery is a public elementary school located on the Upper East Side of Manhattan, in New
York City. For the 1994 to 1995 school year, it employed 45 teachers with a mean of 15 years of teaching experience. In the enrollment of approximately 880 students from kindergarten through the sixth grade, $75 \%$ were Caucasian, 7\% African American, 9\% Latino, and 9\% Asian. Although a large percentage of the parents were professionals, other parents were employed in service jobs at nearby businesses, museums, and hospitals. More recently, an increasing number of neighborhood workers, including building superintendents and housekeepers, had enrolled their children.

\section{Data Collection}

Participants in this study included 12 teachers along with the principal, Ms. Fry, and the staff developer, Ms. Kirk. The teachers were purposely selected (Firestone, 1993; Stake, 2000) to reflect varying backgrounds. The selection process took into account the following dimensions: gender, grade level taught (from $\mathrm{K}$ to 6), and years of teaching experience (ranging from less than 1 year to more than 30 years). The principal first provided a list of teachers who fitted into these categories, and then these teachers were contacted to elicit their participation.

During this study, the author worked as a researcher in a university research center. His access to the school was facilitated by a colleague who had known the principal and teachers in the school for many years. Data for this study were collected from two primary sources: (a) open-ended interviews with the sampled teachers, principal, and staff developer and (b) a collection of portfolio-related documents.

Interviews were important to understand what the portfolio project meant to the participants, to document their thoughts concerning its processes, and to note their perceived change as a result of their involvement. The interviews with the teachers, principal, and staff developer posed a series of parallel questions on the project, which were used so their views of the project could be compared, contrasted, and complemented with data from other relevant documents. Open-ended questions focused on participants' views on the process of doing a 
portfolio and its demands and supporting conditions as well as their perception of the impact of the project. The following are examples of questions: "Could you tell me a little bit about the process of doing a portfolio at Avery? What kinds of adjustments have been made, if any, since the beginning?"

The study was conducted between October 1994 and June 1995. During that time, the participants were interviewed twice, with each interview lasting an average of 50 minutes. All interviews were conducted at the school, and the data were collected on audiotape. The first interview was conducted at the beginning of the school year and was transcribed immediately. Themes derived from preliminary analysis of the first round of interviews were then used to inform the development of the second round of interviews. The second round of interviews were conducted near the end of the school year.

Teaching portfolios were collected from all of the teachers who completed them in the school to take a closer look at the areas of interest and the development of ideas. Other collected documents included students' work, the principal's letters to teachers relating to their portfolios, and teachers' written feedback to the principal. These documents were used to inform the development of interviews, particularly the second round of interviews.

\section{Data Analysis}

Transcripts made of the audiotaped interviews were checked for accuracy against the original recordings. Data analysis was conducted simultaneously with data collection. Analytical files (Glesne \& Peshkin, 1992) were built after a school visit or during the transcription of an audiotape. These files were organized by generic themes such as characteristics of portfolios, beginning the portfolios, and necessary conditions for portfolios. Under each of these themes, preliminary codes emerged as the process went on. For example, the following codes surfaced under "characteristics of portfolios": ongoing; responsive; context oriented; manageable, meaningful, personal, or purposeful; individualized; and a sense of control.
During the final stage of analysis, the constant comparative method (Glaser \& Strauss, 1967) was used to analyze the data from various sources.

First, we tried to have several excerpts that were similar in language before we labeled a category. Then we examined whether the inclusion of the next excerpt in the category would change its meaning. If so, when that excerpt was incorporated, the existing category was modified. If not, we compared this incoming excerpt with those already in that category. We replaced an existing excerpt with the incoming excerpt if it provided a better example to illustrate the category. (Xu \& Corno, 1998, p. 411)

Triangulation of different data sources and different perspectives was used as a means of enhancing internal validity and safeguarding against various biases (Denzin, 1978; Patton, 1990; Yin, 1994). The draft of the study was read by the principal, the staff developer, and all the teachers whose portfolio work or interviews were cited. Half a month later, a 2-hour work-inprogress session was held during which a group of colleagues along with the principal critiqued the draft. Consequently, these comments were used to revise the text to correct factual details, challenge interpretations, or argue for rival explanations. These strategies, member check and collegial exchange, served further to minimize potential biases (Erickson, 1986; Vaughan, 1992).

\section{THE EVOLUTION OF THE PORTFOLIO PROJECT}

The portfolio project evolved from visitors' requests for more information about the school. Initially, Ms. Fry asked five teachers to put together a folder to serve this purpose. Seeing that more teachers were interested in this kind of a project, she used this as an opportunity to encourage each teacher to create a teaching portfolio.

As the process of doing teaching portfolios evolved, so did the purposes for doing them. The emphasis shifted to motivate teachers to think in more depth about what they were doing in classrooms and then to share their work with their colleagues. Thus, a theory of 
action emerged, as Ms. Fry reasoned that if teachers focused on one area of interest and examined it deeply, they would become more reflective not only in that area but also in other areas. Also, if teachers became experts in one area, they had something to share with and learn from one another; this, in turn, could motivate all of them to think more deeply about their work.

A teaching portfolio at Avery included the following three sections: (a) a statement of teaching philosophy (e.g., explaining why such a topic was being pursued); (b) a main entry that documented one's learning in a specific area of interest (e.g., cooperative learning in the third grade) along with practical suggestions for other colleagues; and (c) an inclusion of supplementary materials (e.g., a bibliography and children's artifacts). These materials were to provide justification for the work as well as to enhance individual learning and group sharing.

Each teaching portfolio became a living document at Avery. Although teachers were encouraged to think in-depth in one area of interest, the principal decided where the larger focus would be placed each year. For example, in the second school year of the portfolio project (1994 to 1995), teachers were encouraged to collect and reflect on three samples of student work in the areas of interest: one from an overachieving student, one from an average student, and one from a struggling student. The purpose here was to prompt teachers to more closely examine and adjust their teaching strategies to help students at various levels learn better. As Ms. Kirk explained, it was about "what I do as a teacher to get these kids to move forward, and what am I going to do next?"

As the purposes of the portfolio evolved, so did the audience for whom it was intended. The audience soon expanded from school visitors to include other teachers and the school administration in the building.

\section{IMPACT ON PROFESSIONAL LEARNING}

The data revealed that the portfolio project had a notable positive impact on professional learning, which could be grouped into four categories. The first benefit was that the project enabled teachers at different developmental stages to approach their work more meaningfully and purposefully. It prompted a firstgrade teacher, who was in her second year of teaching, to think through more carefully the steps of everything she did: "What specific goals do I have for each lesson?" and "How can I best meet the needs of the children in my class?" It helped a sixth-grade teacher, who was in her 24th year of teaching, to look inside herself and ask, "What am I doing?" "Why am I doing it?" "Why do I get up in the morning and come here?" and "What are my goals?"

Second, the portfolio project encouraged teachers to take risks, especially for experienced teachers. One fourth-grade teacher with more than 20 years of teaching experience made this general observation on experienced teachers, portfolios, and risk taking: "Most of us here are experienced teachers. But in order to be a good teacher, you have to be a risk taker, because that is really how you unfold." She found the project stimulated teachers to do just that: "I think the whole idea of doing a portfolio is a risk, but it turns out to be one that is well worth taking." Another experienced teacher noted that trying to find ways that would work better in her class meant that she really had to take "a certain amount of risk and experimentation." However, she felt comfortable going ahead because she was not pressed for immediate results. "I was given a kind of time span to test things in. That's really important. It's like I have a kind of freedom to not push myself or expect things before they could reasonably be expected."

Third, the project provided teachers with ongoing learning opportunities. One third-year teacher felt that it provided a starting point to further explore and try out new ideas in her class, such as working with students to develop the rubrics to assess research projects. Similarly, a senior teacher noted that the portfolio project enabled her to incorporate new ideas into her class on an ongoing basis.

It probably makes me search out new ideas to add to my portfolio. When I try something new, I say, 'Oh yes, this can now go into my portfolio if I find a particularly good assessment tool that I did not think of before." 
The project convinced another senior teacher that if teachers stopped learning, they were not going to be able to ignite anyone else.

Closely related to the above-mentioned benefits, the final benefit was that the project helped teachers know their students better and become more responsive to their needs. A fifth-grade teacher in his seventh year of teaching at the school did a portfolio on reading and writing assessment using response letters. Insights gained from writing and organizing his portfolio prompted him to keep in touch with all of his students on a weekly basis, which in turn allowed him to adjust his approach to better support them. Sometimes, he gave mini lessons when common issues arose (e.g., focus and inferences), explaining them with the use of examples from student writing and suggesting how students could better handle such a topic in the future. At other times, he wrote letters back to students illustrating what he wanted them to do. For those having specific problems, he set aside time for individual conferences.

\section{IMPACT ON PROFESSIONAL COLLABORATION}

The data from this study revealed that the portfolio project affected professional collaboration in three ways. First, it became a vehicle for them to learn with and from each other. One teacher said, "It gives us something on paper to use and to share with others about our teaching styles and our ideas. It gives us a chance to talk to each other and to really collaborate."

Particularly, the project became "a common language" to help connect new teachers with experienced teachers. Ms. Kirk observed that new teachers got a chance to see that they had a whole lot to learn from experienced teachers, whereas experienced teachers came to see that new teachers also had some knowledge and insights to offer, although they did not have as many years of teaching experience. One senior teacher commented,

It's like going to a library and finding other books you need to see another person's point of view on the same subject. It's like getting a whole bunch of reference books. I take other teachers' portfolios and look at how they have their children create tests or how they use the writing process, and I then incorporate ideas from that into my portfolio. I have a copy of everybody's portfolio.

The spirit of collaboration grew beyond teaching portfolios. Teachers started coming together on their own during lunch. One reported that the first-grade teachers had lunch in her room, explaining, "We have a casual, off-therecord mini meeting every day." Ms. Fry found that

teachers [now] are not embarrassed to talk about education during the lunchtime. They talk about their problems because they know they are not going to be judged on the fact that they have problems.

So, we have come together as a real family.

Second, the portfolio project changed working relationships between teachers and administrators. Ms. Fry felt that it provided her with rich information about teachers. For example, she said she could go and observe a first-grade teacher; however, "having read her portfolio was a much more insightful way for me to get into her head.... It gives you a very clear picture of how you can help." The project provided her with a vehicle to work with teachers more constructively:

It gives me an opportunity to talk to teachers without threatening them. We can talk about things I believe without saying, "I think you need to do this." There is a teacher, for example, whom I think should be doing a little bit more writing in her class. However, instead of going in and saying, "I think you need to do more writing," I can look at her portfolio and say, "Gee, do you think you really want to do this? A good way to go about this would be to get more writing in the classroom." It gives me a way to talk to the teachers that is not threatening and not authoritative.

Many teachers agreed that the project enabled them to connect better with the administrators. One senior teacher found that it gave her another channel to communicate with them about the "nuances" of classroom teaching. Another senior teacher, who had 28 years of experiences in four different schools, observed:

Very often, you have a sort of parent-child relationship between administrators and teachers. Many of us are at the same age as the principal, we just had different experiences; but I think the portfolios show 
that the administration recognizes our strengths and has respect for the knowledge of other professionals that you are working with, then allowing the staff members to share those talents with others.

Finally, the changed relationships between teachers and administrators, along with the knowledge and confidence gained from writing and sharing their work with their colleagues started to change teachers' stance toward other administrators and university-based experts. One third-grade teacher made a presentation to more than 20 administrators in one conference at her school district. The presentation focused on alternative forms of assessment in thirdgrade social studies, which grew out of a topic in her portfolio. Using China and South Africa as examples, she illustrated a range of materials (e.g., novels and maps) and activities (e.g., rewriting a story from another character's point of view) that one could incorporate. She then shared her experience in using alternative forms of assessment in her class, including doing a research project, making a travel brochure, and asking children to make a test for others to take. In response to some administrators' questions at the end of her presentation, she readily offered her insights about how they could support teachers in their schools with similar initiatives.

For another teacher, the insights gained from working on his portfolio and from trying out new ideas in practice prompted him to examine "expert knowledge" more critically. He attended a writing workshop at a nearby major research university where one expert asserted that it did not make any sense to have students write letters to a teacher about their readings; because the teacher was right there, there was no need for such writing. He felt that the expert failed to understand the time limitations a teacher faces in the real classroom. In addition, he found that response letters afforded him an opportunity to get to know his students better. He learned which type of books appealed most to his students, he heard the "voice" of shy students who rarely spoke throughout the school day, and he saw "a new image" of the big tough kids who consistently wrote about the feelings of younger characters in stories.
Furthermore, some teachers started to view themselves as agents of systematic change. One teacher was interested in the teachers linking their portfolios to the Internet and sharing their ideas with teachers in other schools while learning how they might be using portfolios. Another teacher wanted to "network with teachers across the nation ... to really learn from other systems what they are doing, what has worked for them, how they can improve, and what we can learn from it."

\section{CONDITIONS SUPPORTING PROFESSIONAL LEARNING AND COLLABORATION}

The study revealed that the following two conditions contributed to both professional learning and professional collaboration in general: (a) building an environment of trust and (b) developing a model of supervision consistent with professional learning and collaboration.

Building an environment of trust was essential for both professional learning and collaboration, especially between teachers and administrators. Ms. Fry noted that "teachers have to trust you and you have to trust them," otherwise "nobody wants to get involved." One teacher noticed that because teachers "have a lot of trust in [the principal], doing a portfolio isn't that scary." Similarly, because he had a lot of trust in Ms. Kirk, he felt comfortable discussing ideas and suggestions.

Nurturing open lines of communication played a crucial role in building an environment of trust. Ms. Fry felt that it was "very important to listen, to listen, and to listen." She welcomed teachers to come by her office any time, whether to pick up a piece of candy, borrow a book, or initiate a conversation. Each year, she spent half an hour of uninterrupted time with each teacher to talk "not only about his or her portfolios but also about everything that is happening in their classrooms." Beginning in 1995, she decided to ask each teacher to give her a report card relating to the things she was doing and recommending things she needed to improve. She believed that communication had to be "a twoway street." She added, "It's important that I know what areas I need to work on in the same way I meet with the teachers and tell them what 
areas I think they need to work on." Ms. Kirk observed that these open communication channels made teachers feel that someone was listening to them. One teacher noted, "She's really the first principal I can come to and just say, 'How are you?' and just talk." This made it a lot safer for her to drop by to talk with Ms. Fry about her portfolio or any other concerns.

Another condition was to develop a model of supervision consistent with this emerging view of professional learning and collaboration. Ms. Fry decided that

the teachers doing portfolios are not being observed anymore. They don't have formal classroom observation. Instead of my going there and observing how they teach, the portfolios have become their observations, which is much more powerful than just observing a lesson for 45 minutes on one subject.

This change sent a powerful message to the teachers. One new teacher pointed out the difference "between having administrators sitting in your room watching you and having them help you reflect on what you are saying and writing." One experienced teacher remarked that that meant for the first time in her teaching career, she did not need someone coming in to watch her try to teach "the perfect lesson." Instead, she "can even try something that is not going to work" and then "write about why it did not work."

\section{CONDITIONS MORE SPECIFICALLY SUPPORTING PROFESSIONAL LEARNING}

In addition to those general conditions previously mentioned, the study further showed that it was critical to have conditions that more specifically focus on supporting professional learning. One condition was for both the teachers and the administrators to have a sense of joint control over professional learning. This was realized when the teachers selected an individual area of interest to work on while the principal decided on a larger focus for the school each year. This sense of joint control was especially important for teachers in the beginning. As one teacher observed, it opened up a door for them to think about working on something individually interesting as well as meaningful.
Closely related to a shared sense of control was a desire to keep the project manageable. Ms. Fry was very careful not to overwhelm the teachers. She explained, "It's about taking what they've already got and adding other dimensions." Rather than besieging them all the time with new stuff, she encouraged them to focus on one area of interest and "use the portfolio as a way to bring new initiatives that make sense to them."

Another condition was to provide ongoing assistance based on teachers' needs. Initially, for most teachers, the process of organizing their ideas was their biggest obstacle. Ms. Kirk noted that this was because they had not had such an opportunity since becoming teachers. One teacher agreed: "There is the difficulty of the amount of information involved, the amount of structure, the voice that I'm going to use as a writer, and how it's presented." In response, the school helped teachers articulate and organize their ideas. Ms. Kirk recalled,

It's a process of getting them to use their own words. Either Ms. Fry or I or another person writes back to them, validating what they have said and saying, "Yes, this makes sense." Or we may ask the questions having to do with something that doesn't make sense. . . . Then, there is the gentle nagging in between: "How's it going?" or "What have you done recently?" or "What are you going to do next?"

In addition, the school tried to find out a way to get whatever teachers needed. One teacher elaborated,

Ms. Fry provides funds if you need them. If there's something I want to teach and I don't have the books, she will find a way for me to get those books. She'll go and pick them up herself if she has to.

Many teachers acknowledged the importance of this support. "It would cost a fortune to do it on our own," commented one teacher.

\section{CONDITIONS MORE SPECIFICALLY SUPPORTING PROFESSIONAL COLLABORATION}

It seemed that professional learning via teaching portfolios, supported by various conditions mentioned previously, generated an electric atmosphere for professional collab- 
oration. The experience of writing together produced a sense of camaraderie among the teachers. Ms. Kirk observed,

When you write down who you are, it makes you vulnerable, and that changes relationships between people. They start to see each other in a different way, and they start to be more supportive of each other. They start to encourage each other, and they go to each other's room, asking, "What have you done?" "Come and read mine. Do you like the way it sounds?" So there is a very, very strong networking of people who are writing together.

In addition, a range of incentives emerged from the portfolio process, which served as an additional impetus for professional learning and collaboration. Some teachers saw the great value of doing a portfolio in their teaching context: "This is really something I use. Everything I put into it, I'm using in my classroom." Others felt that reflecting on an area of interest allowed them to become learners themselves, along with their students and their colleagues, and they found such an experience exhilarating and challenging.

Other conditions supporting professional collaboration came from the school's effort to (a) foster a collaborative social climate, (b) publicize teaching portfolios in teachers' work lives, and (c) institute June planning sessions. Ms. Fry often encouraged teachers to learn from their colleagues by connecting teachers to one another and by referring teachers who were just beginning or who were midway in the process to talk with those who had already completed a portfolio. One second-year teacher found that it was nice to know that "so and so did a portfolio on this [the area she was interested in]," so she could "go and ask them if they have any ideas." Ms. Kirk noted that "the first group of teachers got the chance to teach the second group of teachers, so then we had mentors." She observed that it made teachers "willing to work twice as much" because "in this job, nobody ever tells you that." Many teachers agreed that this process gave teachers a sense of recognition both from the school administrators and other teachers: "This gives the teachers the respect they deserve, the sense of professionalism and esteem you get when your work is looked upon with pride and respect."
Another fact that contributed to increased sharing among teachers was that from the beginning, Ms. Fry downplayed the issue of competition:

I have been very careful and I will continue to be very careful when a new group of teachers begins to do portfolios that none of them pick the same topic that anyone else has already done. I don't want teachers to be in competition with each other.

Ms. Fry's effort seemed to pay off. One senior teacher noted that doing a portfolio was about raising "the quality of the work you want for your children, not a competition. But seeing that another teacher can bring this quality of work into her class makes you want to strive also."

One senior teacher observed that teachers used to keep their doors closed and nobody shared anything.

If you were doing something good, you did not tell anybody because you wanted to be a star. The difference now is that everyone is a star and everyone is willing to share. For the first time, I feel I am a member of a community.

At the essence of this transformation was the emergence of a new core of values. As Ms. Fry noted, "Now a teacher has a good idea, she shares it and knows she gets more credit for it than if she keeps it to herself."

In addition, the school tried to expand the audience and make them more visible, as evidenced in the portfolio celebration described at the beginning of this article. Ms. Kirk explained that

the audience has really changed everything, even for teachers whom we thought would never want to do a portfolio, who were very experienced, or who had been doing the same thing in the same way for many years. Because of the excitement, and because there was an audience for their work, and because we had visitors from other schools in the city and around the country coming in to visit and taking portfolios away with them, the energy from this process really convinced these teachers to take the risk and join the others.

Sensing the energy generating from having an audience, Ms. Fry deliberately made "the audience" even more visible. She asked visitors to write a letter of comment after their school visits, and then she circulated these comments 
for teachers in a weekly memo. For example, one visitor commented, "I enjoyed seeing the integration of social studies and literature and how everything was tied into the writing process." To have visitors comment on work that the teachers had done, especially noting ideas and practices that visitors had found particularly informative and valuable, made teachers want to work even harder.

For the most part, the conditions that supported professional collaboration at Avery were loosely structured through promoting a collaborative social climate rather than through making formal organizational arrangements. This probably resulted from the fact that the teaching portfolios as "texts themselves play a critical role in forming and maintaining communities with an inquiry stance" (Cochran-Smith \& Lytle, 1999, p. 295). The portfolios as texts made teacher sharing and collaboration possible without having the teachers be physically together for extended periods of time. However, there was one formal arrangement that was deliberately instituted to promote professional collaboration.

Started in the 1992 to 1993 school year, Ms. Fry scheduled a day in June for teachers in each grade to plan together for the next school year and "to have teachers talk to each other about what they are going to do as a grade." It was a 1day discussion in which "everybody helps make decisions." The teachers talked about the goals for their grades, decided on the books and materials they wanted to order, and envisioned the trips they wanted their students to take.

Ms. Fry noted that this planning session was her way of saying to teachers that

talking is important. If you say it's important but you don't give time [for them to talk], you really don't believe in it. . . My job these days is to get whatever they need and answer any questions they may have.

She provided them with lunch and invited other teachers that the group felt should be there during a particular stage of planning (e.g., a music teacher, a science teacher, a teacher from the previous grade level, or a teacher from the next grade level). As a result, teachers felt that the planning session provided "a continuing ground for dialogue in a friendly setting ... to start to discuss the next year's plan." Ms. Fry noted that the session was very powerful, finding out that her teachers had told other teachers in the district, "If your principal is not doing this, then they shouldn't ask you to do anything else."

\section{CONCLUSION}

This study examined the use of teaching portfolios in promoting school-centered professional development in one urban elementary school. The data revealed that the portfolio project served as a means of generating teacher reflection and collegial sharing in the school community. It provided a sense of purpose and energized teachers at different stages of development to take risks and to examine their practices on ongoing basis. It helped create a sense of affiliation and provided a vehicle for teachers and administrators to work collaboratively and constructively. These findings provide empirical support to the numerous theoretical claims of the viability of school-centered professional development (Darling-Hammond \& McLaughlin, 1995; Fullan, 1995a; Lieberman, 1995; Little, 1993; Loughran, 1994; Loughran \& Gunstone, 1997; Sparks, 1995) and of the importance of providing mechanisms to promote school-centered professional development (Daniel \& Stallion, 1996; Wilson \& Berne, 1999).

Specifically, this study focused on the role of teaching portfolios in teachers' professional development. Consistent with theoretical claims (Shulman, 1998; Wolf, Whinery, \& Hagerty, 1995) and other empirical studies on teaching portfolios (Anderson \& DeMeulle, 1998; Borko, Michalec, Timmons, \& Siddle, 1997; Freidus, 1997; Wade \& Yarbrough, 1996), this study suggests the value of teaching portfolios as mechanisms for promoting reflection and professional learning. In addition, it suggests the value of teaching portfolios as mechanisms for promoting professional collaboration in school communities by providing a vehicle for teachers at different developmental stages to learn with and from each other, to work more constructively with school administrators, and to reach out to other schools as agents for systematic change. 
Furthermore, the study lent empirical support for theoretical arguments regarding the importance of providing supporting conditions for promoting school-centered professional development (Dilworth \& Imig, 1995; Little, 1993; McDiarmid, 1994; Teitel et al., 1998). Specifically, it revealed the critical importance of building three broad sets of conditions to promote school-centered professional development through teaching portfolios. In this study, the route to school-centered professional development started with individual inquiry supported by conditions that specifically focused on professional learning (e.g., keeping the portfolio project manageable) and coupled with other conditions that fostered both professional learning and collaboration (e.g., building an environment of trust). As the process of writing teaching portfolios gave the teachers momentum, purpose, and confidence in their professional learning, professional collaboration with other teachers and school administrators began to surface. In this transition to the second stage, the momentum gained from professional learning itself became a part of the conditions that supported professional collaboration. The route from professional learning to professional collaboration was further facilitated by other relevant conditions that more specifically focused on professional collaboration (e.g., encouraging sharing while discouraging competition) as well as by conditions that served to foster both professional learning and collaboration (e.g., developing a model of supervision consistent with professional learning and collaboration).

Loucks-Horsley (1995) discussed two different views related to promoting professional development. One view argues that professional development cannot be achieved without first substantially restructuring the school. The other view contends that focusing first on changing professional development may prove to be a catalyst for more schoolwide change and restructuring. More recently, in one comprehensive literature review on teacher learning, Cochran-Smith and Lytle (1999) found that there is a continuing debate about what to focus on first to promote teacher learning in commu- nities: whether to start with individual inquiry or schoolwide change. Although "there is a relationship between teacher learning in communities and larger efforts to change the cultures of the schools and teaching," Cochran-Smith and Lytle pointed out, "the exact nature of the relationship of the part to the whole is not so clear" (p. 281).

This study sheds light on the relationship between teacher learning and initiatives to change the cultures of teaching. It lends empirical support to the view that focusing first on promoting professional development may become a catalyst for more schoolwide change. It illustrates the potential of this approach in providing purpose, focus, and substance along with a sense of ownership and belonging in which teachers learn with and from each other.

This study has important implications for anyone interested in crossing the fault line between theory and practice in the area of teacher learning, professional development, or school improvement. First, it can be argued that closely grounded in the data, the study generates a substantive theory (Glaser \& Strauss, 1967) for promoting school-centered professional development through teaching portfolios. That is, the route to school-centered professional development can be achieved through focusing first on individual inquiry and then on professional collaboration supported by three broad categories of conditions with varying emphasis on professional learning and professional collaboration as it makes a transition from the first to the second stage.

Specifically, this study raises the important question of how to extend the use of teaching portfolios beyond preservice years to promote school-centered professional development in school communities. Currently, teaching portfolios have primarily been used as a tool for promoting reflective practice in preservice teacher education programs (Ferraro, 2000; Lyons, 1998b; Wolf \& Dietz, 1998). Empirical support for its use is accumulating, for example, from a case study of one preservice student (Freidus, 1997), a case study of one preservice program (Borko et al., 1997; Wade \& Yarbrough, 1996), 
and a survey of 24 preservice programs in 13 states (Anderson \& DeMeulle, 1998). One urgent and critical issue, however, is how to build up the momentum that has started at these preservice programs and further promote reflective practice through teaching portfolios in school settings. Policy makers and school administrators would benefit from a line of research such as that illustrated in this study, a line of research that examines a wide range of conditions supporting the use of teaching portfolios in school communities and provides a powerful narrative and a theory of action suggesting both the viability of this type of portfolio initiative and the means to make it work in school communities.

In addition, relating to the more general issue of changing cultures of teaching, the concreteness of this type of study could prove valuable as schools struggle with the question of how to change their cultures into ones that promote professional learning and collaboration (Cochran-Smith \& Lytle, 1999; Johnson, 1990). The systematic in-depth study of one school's attempt to do so could point the way to others who recognize such a need but are befuddled by how to facilitate such a change (e.g., lacking the appropriate mechanism and/or supporting conditions).

Finally, research on teacher learning and professional development would benefit from more systematic theorizing about the mechanisms by which teachers learn (Wilson \& Berne, 1999), about the conditions that support school-centered professional development (McDiarmid, 1994; Teitel et al., 1998), and about the relationship between teacher learning and larger efforts to change the cultures of teaching (Cochran-Smith \& Lytle, 1999). The case study such as this, focusing on teacher portfolio as a mechanism and supported by the three sets of conditions outlined, could serve as the breeding ground for insights and hypotheses for further investigation on how to promote schoolcentered professional development. For example, this study focused on the teaching portfolios as they were implemented in one urban elementary school and initiated by the princi- pal. The field would benefit from studying other school-centered professional development initiatives-using teaching portfolios or other mechanisms - at different levels (e.g., in a middle school), in different locations (e.g., in a rural area), and in different situations (e.g., initiated by network or university teacher educators). Examining and comparing conditions under these varying circumstances with different mechanisms and supporting conditions would broaden and deepen our understanding about what school-centered professional development can entail and how it can be better promoted in different contexts.

\section{NOTE}

1. The names of the elementary school and the participants have been changed to maintain their confidentiality.

\section{REFERENCES}

Anderson, R. S., \&, DeMeulle, L. (1998). Portfolio use in twenty-four teacher education programs. Teacher Education Quarterly, 25, 23-31.

Bartell, C. A., Kaye, C., \& Morin, J. A. (1998). Portfolio conversation: A mentored journey. Teacher Education Quarterly, 25, 129-139.

Borko, H., Michalec, P., Timmons, M., \& Siddle, J. (1997). Student teaching portfolios: A tool for promoting reflective practice. Journal of Teacher Education, 48, 345-357.

Cochran-Smith, M., \& Lytle, S. L. (1999). Relationships of knowledge and practice: Teacher learning in communities. In A. Iran-Nejad \& P. D. Pearson (Eds.), Review of research in education (Vol. 24, pp. 249-305). Washington, DC: American Educational Research Association.

Daniel, P. L., \& Stallion, B. K. (1996). Implementing schoolbased professional development in Kentucky. Journal of Staff Development, 17(4), 30-32.

Darling-Hammond, L., \& McLaughlin, M. W. (1995). Policies that support professional development in an era of reform. Phi Delta Kappan, 76, 597-604.

Denzin, N. K. (Ed.). (1978). The research act: A theoretical introduction to sociological methods. New York: McGrawHill.

Dilworth, M., \& Imig, D. G. (1995). Professional teacher development. The ERIC Review, 3, 5-11.

Erickson, F. (1986). Qualitative methods in research on teaching. In M. Wittrock (Ed.), Handbook of research on teaching (3rd ed., pp. 119-161). New York: Macmillan.

Ferraro, J. M. (2000). Reflective practice and professional development (ERIC digest). Washington, DC: ERIC Clearing- 
house on Teaching and Teacher Education, American Association of Colleges for Teacher Education.

Firestone, W. A. (1993). Alternative arguments for generalizing from data as applied to qualitative research. Educational Researcher, 22(4), 16-23.

Freidus, H. (1997, March). The telling of story: Teachers knowing what they know. Paper presented at the annual meeting of the American Educational Research Association, Chicago.

Fullan, M. (1995a). The limits and potential of professional development. In T. Guskey \& M. Huerman (Eds.), Professional development in education: New paradigms and practices (pp. 253-267). New York: Teachers College Press.

Fullan, M. (1995b). The school as a learning organization: Distant dreams. Theory into Practice, 34, 230-235.

Glaser, B. G., \& Strauss, A. L. (1967). The discovery of grounded theory: Strategies for qualitative research. Hawthorne, NY: Aldine.

Glesne, C., \& Peshkin, A. (1992). Becoming qualitative researchers: An introduction. White Plains, NY: Longman.

Grant, G. E., \& Huebner, T. A. (1998). The portfolio question: the power of self-directed inquiry. In N. Lyons (Ed.), With portfolio in hand: Validating the new teacher professionalism (pp. 156-171). New York: Teachers College Press.

Johnson, S. M. (1990). Teachers at work. New York: Basic Books.

Kirshner, D., \& Whitson, J. (Eds.). (1997). Situated cognition: Social, semiotic, and psychological perspectives. Hillsdale, NJ: Lawrence Erlbaum.

Lieberman, A. (1995). Practices that support teacher development: Transforming conceptions of professional learning. Phi Delta Kappan, 76, 591-596.

Little, J. W. (1993). Teachers' professional development in a climate of educational reform (NCREST reprint series). New York: National Center for Restructuring Education, Schools and Teaching, Teachers College, Columbia University.

Lord, B. (1994). Teachers' professional development: Critical colleagueship and the role of professional communities. In N. Cobb (Ed.), The future of education: Perspectives on national standards in education (pp. 175-204). New York: College Entrance Examination Board.

Loucks-Horsley, S. (1995). Professional development and the learner centered school. Theory into Practice, 34, 265271.

Loughran, J. (1994). Professional development for science teachers: A school based approach. Science Educational International, 4(4), 25-28.

Loughran, J., \& Gunstone, R. (1997). Professional development in residence: Developing reflection on science teaching and learning. Journal of Education for Teaching, 33, 159-178.

Lyons, N. (1998a). Reflecting in teaching: Can it be developmental? A portfolio perspective. Teacher Education Quarterly, 25, 115-127.
Lyons, N. (Ed.) (1998b). With portfolio in hand: Validating the new teacher professionalism. New York: Teachers College Press.

McDiarmid, G. W. (1994). Realizing new learning for all students: A framework for the professional development of Kentucky teachers (Prepared for the Partnership for Kentucky School Reform). East Lansing, MI: National Center for Research on Teacher Learning, Michigan State University.

Miller, E. (1998). The old model of staff development survives in a world where everything else has changed. In R. Tovey (Ed.), Professional development: Harvard education letter, Focus series 4 (pp. 1-3). Cambridge, MA: The Harvard Education Letter.

Patton, M. P. (1990). Qualitative evaluation and research methods (2nd ed.), Newbury Park, CA: Sage.

Perez, K., Swain, C., \& Hartsough, C. S. (1997). An analysis of practices used to support new teachers. Teacher Education Quarterly, 25, 41-52.

Shulman, L. S. (1998). Teacher portfolios: A theoretical activity. In N. Lyons (Ed.), With portfolio in hand: Validating the new teacher professionalism (pp. 23-37). New York: Teachers College Press.

Sparks, D. (1995). A paradigm shift in staff development. The ERIC Review, 3, 2-4.

Stake, R. (2000). Case studies. In N. K. Denzin \& Y. S. Lincoln, (Eds.), Handbook of qualitative research (2nd ed., pp. 435-454). Thousand Oaks, CA: Sage.

Stone, B. A. (1998). Problems, pitfalls, and benefits of portfolios. Teacher Education Quarterly, 25, 105-114.

Teitel, L., Ricci, M., \& Coogan, J. (1998). Experienced teachers construct teaching portfolios: A culture of compliance vs. a culture of professional development. In N. Lyons (Ed.), With portfolio in hand: Validating the new teacher professionalism (pp.143-155). New York: Teachers College Press.

Vaughan, D. (1992). Theory elaboration: The heuristics of case analysis. In C. C. Ragin \& H. S. Becker (Eds.), What is case? Exploring the foundations of social inquiry (pp. 173202). New York: Cambridge University Press.

Wade, R. C., \& Yarbrough, D. B. (1996). Portfolios: A tool for reflective thinking in teacher education? Teaching and Teacher Education, 12, 63-79.

Wagenen, L. V., \& Hibbard, K. M. (1998). Building teacher portfolios. Educational Leadership, 55(5), 26-29.

Wilson, S. M., \& Berne, J., (1999). Teacher learning and the acquisition of professional knowledge: An examination of research on contemporary professional development. In A. Iran-Nejad \& P. D. Pearson (Eds.), Review of Research in Education (Vol. 24, pp. 173-209). Washington, DC: American Educational Research Association.

Wolf, K. (1996). Developing an effective teaching portfolio. Educational Leadership, 53, 34-37.

Wolf, K., \& Dietz, M. (1998). Teaching portfolios: Purposes and possibilities. Teacher Education Quarterly, 25, 9-22.

Wolf, K., Whinery, B., \& Hagerty, P. (1995). Teaching portfolios and portfolio conservations for teacher educators and teachers. Action in Teacher Education, 17, 30-39. 
Xu, J., \& Corno, L. (1998). Case studies of families doing third-grade homework. Teachers College Record, 100, 402436.

Yin, R. K. (1994). Case study research: Design and methods (2nd ed.). Beverly Hills, CA: Sage.
Jianzhong $\mathbf{X u}$ is an associate professor at Mississippi State University in Starkville, Mississippi. His specializations include homework, school-family partnerships, cultural diversity, program evaluation, and qualitative research. 